\title{
Hérnia diafragmática em equino: relato de caso
}

\section{Diaphragmatic hernia in horse: case report}

\author{
Augusto Jose Savioli de Almeida Sampaio ${ }^{1 *}$ \\ Fernanda Tamara Neme Mobaid Agudo Romão²; Fábio Morotti³; \\ Guilherme de la Penha Chiacchio Fernandes ${ }^{4}$; Elisângela Olegário da Silva ${ }^{5}$; \\ Giovana Wingeter di Santis ${ }^{6}$; Luiz Francisco Zanella
}

\begin{abstract}
Resumo
A hérnia diafragmática é uma causa rara de cólica em equinos, podendo ser de origem congênita ou adquirida. Comumente, o intestino encontra-se envolvido nos casos de hérnia diafragmática, sendo que o quadro clínico está relacionado ao segmento intestinal envolvido e a extensão da obstrução intestinal, podendo ocorrer desde uma obstrução simples até um processo estrangulante. Frequentemente, os sinais clínicos se caracterizam por desconforto abdominal agudo de intensidade grave, dispneia e/ ou taquipneia. O diagnóstico de hérnia diafragmática pode ser difícil, e na maioria das vezes só é estabelecido durante o procedimento cirúrgico ou na necropsia. O presente trabalho relata a ocorrência de uma hérnia diafragmática em um garanhão, quarto de milha de 14 anos de idade apresentando sinais de desconforto abdominal agudo. O exame físico revelou taquicardia, taquipneia e ausência de motilidade intestinal. A análise do líquido peritoneal mostrou turbidez, aumento de leucócitos e aumento de proteína. $\mathrm{O}$ equino foi submetido à laparotomia exploratória, mas devido à presença de mesentério hemorrágico, isquemia intestinal e encarceramento irredutível do jejuno em forâmen epiplóico, decidiuse pela eutanásia. Além destes achados, na necropsia, foi observada uma hérnia diafragmática com presença de intestino delgado no tórax.
\end{abstract}

Palavras-chave: Hérnia diafragmática, equino, cólica

\footnotetext{
Abstract

The diaphragmatic hernia is a rare cause of colic in equine and may be congenital or acquired. The intestine is commonly involved in cases of diaphragmatic hernia, and clinical signs are related to the intestinal segment involved and the extension, obstruction may occur from a simple process to a strangulating. Often, clinical signs are characterized by acute abdominal whit severe pain, dyspnea and tachypnea. The diagnosis of diaphragmatic hernia can be difficult, and in most cases only is established during surgery or at necropsy. This paper reports a diaphragmatic hernia case in a quarter horse stallion, with 14 years of age showing acute abdominal signs. The clinical examination showed tachycardia, tachypnea and absence of intestinal motility. Turbidity, increase of leukocytes and protein was observed

${ }^{1}$ Prof. Associado do Dept ${ }^{\circ}$ de Clínicas Veterinárias, Centro de Ciências Agrárias, CCA, Universidade Estadual de Londrina, UEL, Londrina, PR. E-mail: asampaio@uel.br

${ }^{2}$ Pós-Graduanda da UEL, Londrina, PR. E-mail: fer_mobaid@hotmail.com

${ }^{3}$ Prof. Assistente do Dept ${ }^{\circ}$ de Clínicas Veterinárias, CCA, UEL, Londrina, PR. E-mail: fabiomorotti@hotmail.com

${ }^{4}$ Residente em Clínica Médica, Cirúrgica e Reprodução de Grandes Animais, UEL, Londrina, PR. E-mail: guifernandes.vet@, gmail.com

${ }^{5}$ Residente em Patologia Animal, UEL, Londrina, PR. E-mail: elivet02@gmail.com

${ }^{6}$ Prof $^{a}$ Adjunto do Dept ${ }^{\circ}$ de Medicina Veterinária Preventiva, DMVP/UEL, Londrina, PR. E-mail: gio@hotmail.com

${ }^{7}$ Prof. Adjunto do Dept ${ }^{\circ}$ de Clínicas Veterinárias, CCA/UEL, Londrina, PR. E-mail: lfzanella@uel.br

* Autor para correspondência
} 
in the analysis of peritoneal fluid. Exploratory laparotomy was performed, but due to the presence of hemorrhagic mesentery, intestinal ischemia, and irreducible incarceration of the jejunum in epiploic foramen, euthanasia was decided. Furthermore, at necropsy, was observed a diaphragmatic hernia with presence of the small intestine in the thorax.

Key words: Diaphragmatic hernia, equine, colic

\section{Introdução}

A hérnia é a uma afecção congênita ou adquirida que se caracteriza pela protrusão de um órgão ou parte dele, através de um defeito na parede de uma cavidade anatômica, na qual se situa o órgão. $\mathrm{Na}$ hérnia congênita o defeito já esta presente ao nascimento e na hérnia adquirida o defeito ocorre após o nascimento, na maioria das vezes associada a um trauma (READ; BELLENGER, 2007).

As hérnias diafragmáticas também são denominadas de falsas hérnias, por não apresentarem as vísceras herniadas contidas no saco herniário. Portanto o termo, ruptura diafragmática, seria a melhor forma de definir esta afecção (READ; BELLENGER, 2007; KELMER; KRAMER; WILSON, 2008). Entretanto, o termo hérnia diafragmática será utilizado neste trabalho por ser a forma mais empregada na literatura.

Embora a hérnia diafragmática seja uma patologia incomum nos equinos, frequentemente, esta associada a sinais de desconforto abdominal (GOEHRING; DOODROCH; MURRAY, 1999). A forma adquirida é a mais prevalente e sua ocorrência esta relacionada aos fatores que causam aumento da pressão abdominal (HASSEL, 2007; SANTSCHI et al., 1997; KELMER; KRAMER; WILSON, 2008; HART; BROWN, 2009; ROMERO; RODGERSON, 2010).

Os equinos com hérnia diafragmática podem apresentar uma variedade de sinais clínicos incluindo intolerância ao exercício, letargia, taquipneia, dispneia e desconforto abdominal com diferentes graus de dor (HASSEL, 2007).

O diagnóstico é realizado com base nos achados de anamnese, exame físico e exames complementares (KELMER; KRAMER; WILSON,
2008). Em muitos casos, a hérnia diafragmática só é diagnosticada na cirurgia ou na necropsia, em decorrência da dificuldade de identificar o defeito ao longo do diafragma (HASSEL, 2007).

$O$ tratamento consiste na redução da hérnia e reparo do defeito diafragmático através da laparotomia exploratória ou por outros acessos. Entretanto, o sucesso desta intervenção cirúrgica depende da possibilidade de acesso ao ponto de ruptura, para adequada reposição das vísceras herniadas na cavidade abdominal e correção do defeito no diafragma (ALVARENGA; SILVA, 1991; KELMER; KRAMER; WILSON, 2008).

O objetivo deste artigo é descrever um caso crônico de hérnia diafragmática atendido no hospital veterinário da Universidade Estadual de Londrina.

\section{Relato de Caso}

Um garanhão, de 14 anos de idade, da raça Quarto de Milha foi encaminhado para atendimento com sinais de desconforto abdominal agudo. Ao exame físico foi observado taquicardia, taquipneia, apatia, mucosas congestas com halo toxêmico, TPC 3" e na auscultação ausência de motilidade (silêncio) em todos os quadrantes abdominais. A palpação retal revelou distensão de intestino delgado. O líquido peritoneal apresentou aspecto turvo, aumento de proteína e aumento do número total de leucócitos. A avaliação laboratorial revelou leucopenia, hemoconcentração, hiperfibrinogenemia e azotemia. Com base nos achados clínicos, laboratoriais e intensidade da dor, o animal foi submetido à laparotomia exploratória. A laparotomia revelou mesentério com aspecto hemorrágico e isquemia de diferentes segmentos de intestino delgado com depósitos de fibrina e encarceramento irredutível de 
parte do jejuno em forâmen epiplóico. Devido aos achados, a exploração cirúrgica foi interrompida e decidiu-se pela eutanásia.

No exame necroscópico observou-se ruptura diafragmática na porção ventral do pilar diafragmático direito (3 $\mathrm{cm}$ de diâmetro) (Figura 1A), com presença de aproximadamente $130 \mathrm{~cm}$ de intestino delgado (porção final do jejuno), epíplon e grande quantidade de fibrina em cavidade torácica (Figura 1B). A mucosa intestinal apresentava-se enegrecida com equimoses e sufusões multifocais. $\mathrm{Na}$ região da junção jejuno-íleo constatou- se espessamento da mucosa com disposição transversal (aproximadamente $10 \mathrm{~cm}$ ), coloração vermelha com áreas enegrecidas e fibrina. Tal área corresponde ao segmento intestinal encarcerado na hérnia diafragmática. Presença de 10 e 20 litros de líquido serosanguinolento em cavidades torácica e abdominal, respectivamente. A pleura e o peritônio parietais estavam espessados, com superfície irregular, petéquias, equimoses e sufusões multifocais. No pulmão evidenciou-se atelectasia e enfisema predominantemente nos lobos apicais e sufusões multifocais. Os demais órgãos não apresentaram alterações patológicas significativas.

Figura 1. Achados macroscópicos e histopatológicos de Hérnia Diafragmática em Equino. Cavidade torácica com insinuação de segmento de jejuno (A). Cavidade torácica com alças intestinais de intestino delgado (B). Corte do anel herniário mostrando extenso tecido fibroso (azul) com presença de vascularização (setas). Tricrômio de Masson, bar- $10 \mu \mathrm{m}(\mathrm{C})$. Segmento de intestino delgado encarcerado com acentuada necrose das vilosidades e hemorragia estendendo-se da lâmina própria à submucosa. H\&E, bar-100 $\mu \mathrm{m}$ (D).

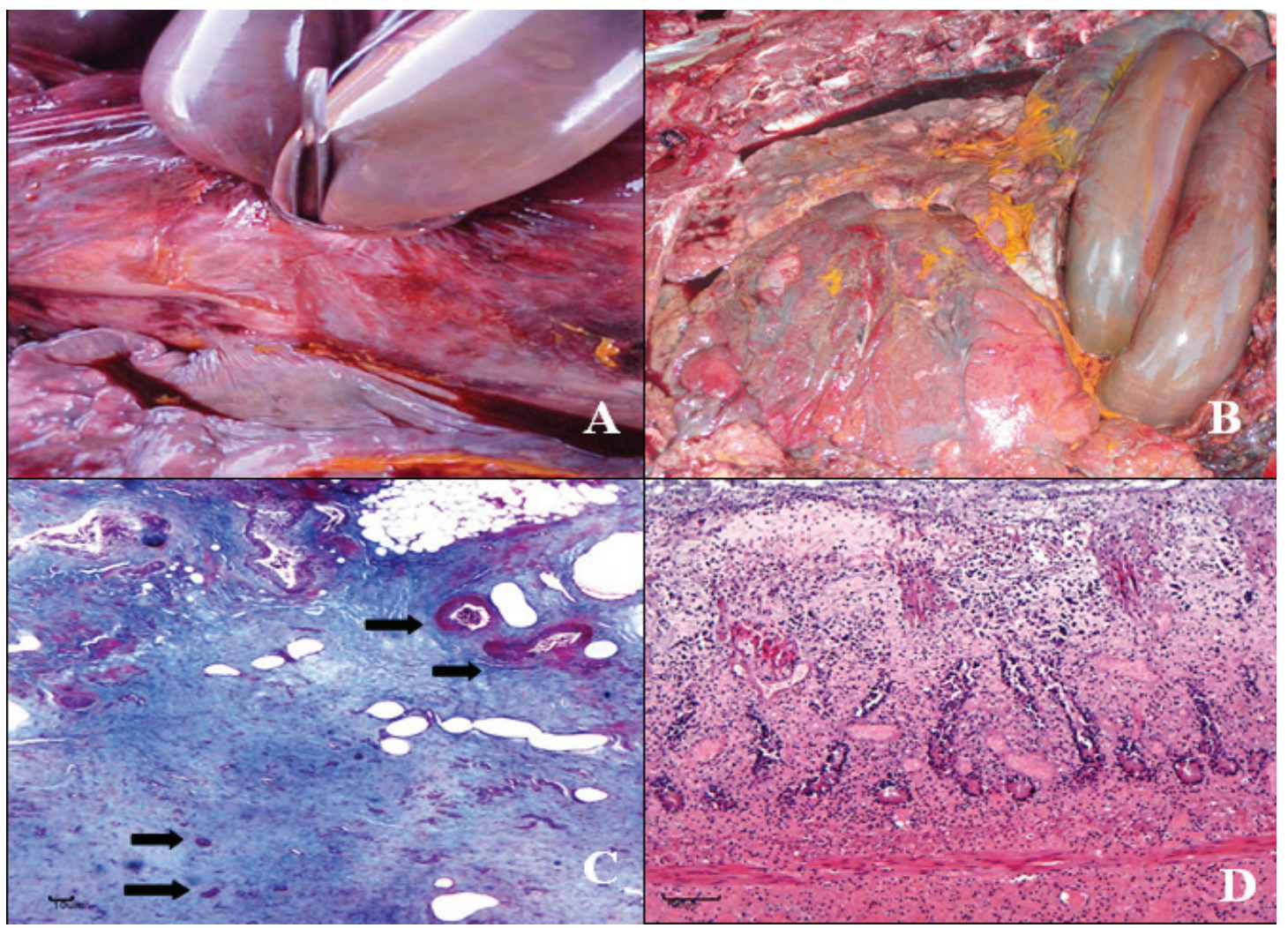

Fonte: Elaboração dos autores. 
Fragmentos do anel herniário e do segmento intestinal encarcerado foram colhidos e fixados em solução de formalina tamponada a 10\%. Após a fixação, foram seccionados e subsequentemente desidratados, diafanizados e incluídos em parafina. Cortes de $4 \mu \mathrm{m}$ foram realizados e submetidos à coloração de Hematoxilina e Eosina para avaliação histológica. A avaliação microscópica do anel herniário evidenciou extenso foco de tecido fibroso com pouca celularidade, e vascularização (Figura 1C). No intestino delgado (junção jejuno-íleo) observou-se acentuada necrose das vilosidades e extensa hemorragia se estendendo da lâmina própria à submucosa (Figura 1D). Presença de infiltrado inflamatório predominantemente neutrofílico na superfície e lâmina própria, e linfocitário na submucosa e camada muscular. Os achados microscópicos revelaram cronicidade da hérnia e necrose isquêmica no intestino delgado (junção jejuno-íleo).

\section{Discussão e Conclusão}

A hérnia diafragmática adquirida é a forma mais prevalente de hérnia diafragmática (SANTSCHI et al., 1997; HART; BROWN, 2009; ROMERO; RODGERSON, 2010). Sua ocorrência esta relacionada aos fatores que causam o aumento da pressão abdominal, como partos, fraturas de costela, traumas e exercícios extenuantes (HASSEL, 2007; KELMER; KRAMER; WILSON, 2008; HART; BROWN, 2009). No caso relatado, não foi possível estabelecer a causa do rompimento diafragmático, pois no momento do atendimento clínico, não havia sinais de rompimento recente do diafragma e segundo a literatura a maioria dos casos descritos ocorreu desta maneira (KELMER; KRAMER; WILSON, 2008). O início e a gravidade dos sinais clínicos dependem dos diferentes órgãos envolvidos, do grau de lesão vascular e do comprometimento respiratório (KELMER; KRAMER; WILSON, 2008). Intolerância ao exercício, letargia, taquipneia, dispneia e desconforto abdominal com diferentes graus de dor são os sinais clínicos comumente observados nos casos de hérnia diafragmática (HASSEL, 2007). Quando há encarceramento do intestino delgado, os sinais clínicos são agudos e com presença de desconforto abdominal intenso. Neste aspecto, a hérnia diafragmática com encarceramento intestinal e outras cólicas decorrentes de processos estrangulativos são praticamente indistinguíveis, como observado neste relato (KELMER; KRAMER; WILSON, 2008).

A presença de dispneia é considerada um sinal clínico muito importante para se determinar casos de hérnia diafragmática, entretanto, esta pode ou não estar presente (MOLL et al., 1999). A ausência de dispneia observada neste relato pode estar relacionada ao tamanho do defeito diafragmático (diâmetro muito pequeno $-3 \mathrm{~cm}$ ) e ao selamento do mesmo pelo segmento de jejuno encarcerado e aderência do epíplon.

O tempo de evolução, desde a ruptura diafragmática até o início dos sinais clínicos é muito variável, com duração de poucas horas e até mesmo anos (KELMER; KRAMER; WILSON, 2008; ROELVINK; SLOET van OLDRUITENBORGHOOSTERBAAN; CALSBEEK, 1993). O exame histopatológico do anel herniário revelou um extenso foco de tecido fibroso e pouca celularidade demonstrando a cronicidade da hérnia.

Em muitos casos o diagnóstico é realizado no momento da cirurgia ou necropsia devido a dificuldade de identificar a localização do defeito ao longo do diafragma. Em um levantamento dos casos de hérnia diafragmática relatados na literatura, cerca de $40 \%$ dos casos foram diagnosticados somente na necropsia (HASSEL, 2007; KELMER; KRAMER; WILSON, 2008).

Em equinos com cólica, o diagnóstico pré-cirúrgico da hérnia diafragmática é muito difícil de ser realizado em virtude dos sinais clínicos não demonstrarem comprometimento torácico (SANTSCHI et al., 1997). No caso relatado, o diagnóstico foi realizado durante a necropsia, pois os sinais clínicos, os achados do exame de palpação retal e do líquido peritoneal são 
comuns a outras causas de cólicas e isoladamente não podem ser considerados para se estabelecer o diagnóstico de hérnia diafragmática.

$\mathrm{Na}$ laparotomia exploratória foi observado mesentério com aspecto hemorrágico e isquemia de diferentes segmentos de intestino delgado com depósitos de fibrina. Além disso, foi encontrado um encarceramento irredutível do jejuno no forâmen epiplóico que explicou todos os achados encontrados no exame clínico pré-cirúrgico. Diante dos achados, a exploração cirúrgica foi interrompida e indicou-se a eutanásia.

$\mathrm{Na}$ necropsia observou-se um defeito no diafragma, localizado no pilar diafragmático direito, com presença do intestino delgado na cavidade torácica. Estes achados estão de acordo com o relatado por Kelmer, Kramer e Wilson (2008), onde parte dos defeitos no diafragma ocorre na localização acima descrita e o intestino delgado é a víscera mais comumente encontrada na cavidade torácica.

A descrição deste relato reforça que as cólicas decorrentes de hérnia diafragmática podem ter a mesma apresentação clínica de outras cólicas de origem estrangulante e seu diagnóstico se torna especialmente complexo quando as duas condições estão associadas.

\section{Referências}

ALVARENGA, J.; SILVA,L.C.L.C. Hérnia diafragmática em equino. Relato de um caso. Agropecuária Técnica, Areia, v. 12, n. 1-2, p. 55-59, 1991.
GOEHRING, L. S.; DOODROCH, L. R.; MURRAY, M. J. Tachypnea associated with a diaphragmatic tear in a horse. Equine Veterinary Journal, Malden v. 31, n. 5, p. 443-446, 1999.

HART, S. K.; BROWN, J. A. Diaphragmatic hernia in horses: 44 cases (1986-2006). Journal of Veterinary Emergency and Critical Care, San Antonio, v. 19, n. 4, p. 357-362, 2009.

HASSEL, D. M. Thoracic trauma in horses. Veterinary Clinics of North America: Equine Practice, Philadelphia, v. 23, n. 1, p. 76-77, 2007.

KELMER, G.; KRAMER, J.; WILSON, D. A. Diaphragmatic hernia: etiology, clinical presentation, and diagnosis. Comp Cont Ed Equine Edition, Yardley, v. 3, p. 28-35, 2008.

MOLL, H. D.; WALLACE, M. A.; SYSTEL, A.; CHERAMIE, H. S. Large colon strangulation due to a diaphragmatic hernia in a mare: a case report. Journal of Equine Science, Tokyo, v. 19, n. 1, p. 58-59, 1999.

READ, R. A.; BELLENGER, C. R. Hérnias. In: SLATTER, D. Manual de cirurgia de pequenos animais. 3. ed. Barueri: Manole, 2007. p. 446-448.

ROELVINK, M. E. J.; SLOET van OLDRUITENBORGH-OOSTERBAAN, M. M.; CALSBEEK, H. C. Chronic diaphragmatic hernia in the horse. Equine Veterinary Education, Malden, v. 5, n. 5, p. 255-258, 1993.

ROMERO, A. E.; RODGERSON, D. H. Diaphragmatic herniation in the horse: 31 cases from 2001-2006. Canadian Veterinary Journal, Guelph, n. 51, p. 12471250, 2010.

SANTSCHI, E. M.; JUZWIAK, J. S.; MOLL, H. D.; SLONE, D. E. Diaphragmatic hernia repair in three young horses. Veterinary Surgery, Malden, v. 26, n. 3, p. 242-245, 1997. 
